\title{
Does Female Education Affect Fertility Behaviour in Pakistan?
}

\author{
Zeba AYesha SATHAR*
}

\begin{abstract}
The study explores the relationship between female education and fertility in Pakistan and is based on data from the Pakistan Fertility Survey 1975. Only slight differentials were identified between women with no education and those who had primary or less schooling. However, women with more than primary education had notably lower fertility. Also the role of the intermediate variables such as proportions married, length of breast-feeding and contraceptive use had significant associations with female education.
\end{abstract}

\section{INTRODUCTION}

Studies on the association between female education and fertility probably claim one of the largest shares in the body of the existing literature on the "correlates" of fertility. Several good reviews are now available on this topic which enable a stock-taking of the numerous studies to see whether there is any conclusive evidence that education does in fact have an association with fertility $[7 ; 10]$.

The reviews have found that in most cases a negative association was established between measures of education and fertility. However, there were cases where no association was found or where it was non-linear or, contrary to the expectation, non-negative [7]. Also, questions were raised about the very basis of the studies conducted in this area: for instance, the 'conceptualization' of education in most studies was left unclear and therefore any interpretation of the empirical results was inconclusive and difficult [10]. It was also found that the level of development of a society probably has a bearing on the relationship observed, as have the nature of the educational system and its distribution [26]. Cross-national studies which found an association between education and fertility were thought to contain the effects of ethnicity, religion and economic differences where insufficient controls for these factors were not introduced. These considerations seemed to encourage the idea that the association between education and fertility ought to be studied across

*The author is Research Demographer at the Pakistan Institute of Development Economics, Islamabad (Pakistan). 
a population which was relatively homogeneous with respect to ethnicity, nationality, religion, etc., to eliminate some of the major sources of spurious correlation. This study is an attempt to explore whether female education has any impact on fertility and related behaviour in Pakistan.

A review of the relevant literature specifically on Pakistan found no association between literacy and fertility when the 1961 Census district-level data were used [9]. However, two smaller city-based sample studies found more significant negative associations between the two variables $[1 ; 28]$. An elaborate study based on the National Impact Survey 1969, which used a simultaneous-equation model, found that wife's education affected completed family size negatively in rural areas but did not seem to be relevant in urban areas [13]. This study included both measures of income and husband's education each of which has differing effects in rural and urban areas and may be reflective of interaction between residence and these socioeconomic variables. In a later study based on PFS data, the number of children ever born was found to be affected by both respondent's and husband's educational level but emerged as a significant predictor only in cases in which the man or woman had secondary or higher education [6] .

\section{The Educational System in Pakistan}

The educational system is a legacy of the British system, though after nearly 40 years of independence it has been altered by the infusion of many Islamic and Pakistani cultural ideas and influenced by changes in national education policy. Most educational institutions are publicly financed, though the higher education is more heavily subsidized than primary schooling [16]. Despite Government citations of priority to be attached to the achievement of universal primary schooling, intrasectoral funds have been allocated in such a way as to create a "top-heavy" educational system.

On the whole, expenditure on education in Pakistan has been quite low, even meagre in comparison with the corresponding expenditure in other Asian countries [27]. Due to high fertility there is a large geometric increase in the numbers constituting the school-age population and this implies that educational facilities have to be constantly stepped up rather than kept constant just to keep proportions of educational attainment the same. The percentage of GNP apportioned to education has in fact not risen very much and though the absolute numbers of teachers, schools and students have increased since 1950, there was still a 75-percent illiteracy in Pakistan in 1972 [15]

About three-fourths of the population resides in the rural areas, whereas most schools and almost all colleges and universities are situated in the major towns and cities. Thus, illiteracy is very prevalent in the rural areas and 85.7 percent of the population aged ten or more was illiterate there; the corresponding percentage of the illiterate in urban areas was 58.5 [15]. Apart from the problem of shortage of schools and teachers in the rural areas, there is the more neglected problem of what is taught in most schools. The curriculum is not revised regularly, and learning by rote is encouraged. The irrelevance of the curriculum to the lives of most rural children is thought to be a strong reason for the high drop-out rate in primary schools.

The most important aspect of the educational system, from our point of view, is the strikingly low educational achievement amongst Pakistani females. The literacy rate amongst females aged ten and over was 11.6 percent; in rural areas this rate was a meagre 4.7 percent while in the urban areas it was 30.9 percent in 1972 [15].$^{1}$ The rude fact is that hardly any girls at all attend school in the rural areas: some reasons for this are that in an Islamic society it is much preferred that females and males be segregated, especially after puberty. Segregation is a mechanism adopted to ensure sexual chastity and purity-a state very closely tied up with the concept of "honour" amongst Muslim families. This is not to say that all females beyond the age of puberty observe purdah but that a certain modesty in dress and a strong encouragement of segregation do prevail in the society. This, coupled with the facts that girls are expected to marry early and very few women (around 10 percent) participate in the labour force, is usually thought to be responsible for the lower demand for the schooling of girls in Pakistan. However, the society is undergoing social and economic changes and the attitude of parents towards the schooling of their daughters is likely to change as has already happened in urban areas. This change is reflected in the larger differences in female literacy across urban and rural areas at the 1981 Census. According to that census, urban female literacy went up to 37.3 percent as compared to 7.3 percent for rural areas. The reader must be cautioned that the census figures have not yet been fully tested for comparability with earlier censuses.

To sum up, Pakistan seems to have an educational system which disfavours the chances of females, particularly those residing in rural areas, being schooled. The fault for this lies in both the low demand for education amongst this group and the low expenditure allocated to the sector.

\section{Conceptualization of Education}

One major issue which also emerged from reviews of the literature on education and fertility is that much of the analysis and interpretation of the empirical results depended on the discipline of the researcher. For instance, years of schooling are assumed by economists to have indirect effects on a couple's family size through (a) the effect of total earnings a couple has at its disposal and (b) the

${ }^{1}$ The corresponding rates for males were 30.2 percent for all Pakistan and 22.6 percent and 49.9 percent for the rural and urban areas respectively. 
effect on the opportunity cost of the time required to raise children. If children are time-intensive, the second of these effects is predicted to act to reduce a couple's fertility desires whereas the first would imply that fertility would rise with earnings as long as children remain, in the economic sense, normal goods. Thus, with this orientation both a positive and a negative association between education and fertility can be rationalized.

Sociologists would interpret a positive and a negative association quite differently. For example, in a Turkish study a positive relationship between husband's education and fertility and a negative one between wife's education and fertility were interpreted accordingly: since there were so few educated women there, they represented a very special cultural and socio-economic elite whose sex-role definitions were likely to be different from those of the rest of the population. Consequently, larger fertility differentials were identified. On the other hand, in the case of husbands, well-educated Turkish men were not expected to depart as much from their conventional sex-roles, and their fertility was less likely to be different [20].

We are influenced by the latter approach and mean to adopt a woman's level of education as a measure of her relative access to socio-economic status in the society. Each additional level of educational attainment is thought to represent greater access to a more "modern" experience and a higher standard of living. "Modern" is used to encompass characteristics like a more positive attitude towards controlling family size, better spousal communication, and improved prospects of marrying a more educated man, of having a more equal relationship and of having alternative vocations, such as work and study, rather than being wholly confined to motherhood. Living standard is expected to be positively associated with educational level because higher education is found to assure better access to jobs, especially the white-collar ones [18]. For educated women it probably does not represent their own potential or actual income as much as it reflects the income of their husbands or parents. We acknowledge the difficulty of isolating the true "independent" effect of education on fertility and concede that we are unable to do so because of data constraints. We will in the paper always refer to the effect of education not as that of the content of learning on fertility but as one which is representative of all the features which lead to its acquisition in Pakistan. ${ }^{2}$

Thus the points to be investigated are (a) whether any differentials by education do exist in Pakistan, (b) whether educated women show any motivation to want to have fewer children, (c) whether they have better access to methods of fertility control, and (d) whether there are any natural constraints which give rise to fertility differentials across the education groups.

${ }^{2}$ The association of husband's level of education and fertility was also studied, using PFS data, but it was found to be of far less magnitude than wife's education and was therefore left out of the discussion.

\section{EMPIRICAL FINDINGS}

The Pakistan Fertility Survey of 1975 was utilized for most of the research findings included in this paper. Details of the survey are available in the First Country Report, which included a national sample of 4952 ever-married women [17]. The three groupings made of educational levels consist of women (i) with no education, (ii) with primary or less education, and (iii) with more than primary education. They comprised 86.7 percent, 7.7 percent, and 5.6 percent, respectively, of the sample of ever-married women. The group with more than primary schooling in particular and even the group with primary or less education may be more subject to sampling errors because of their smaller numbers of observations.

Table 1

Fertility Rates by Educational Level of Women (0-4 Years before the Survey)

\begin{tabular}{|c|c|c|c|c|c|c|}
\hline \multirow{2}{*}{$\begin{array}{l}\text { Mother's } \\
\text { age at } \\
\text { the time } \\
\text { of giving } \\
\text { birth }\end{array}$} & \multicolumn{3}{|c|}{ Marital Fertility Rates } & \multicolumn{3}{|c|}{ Age-specific Fertility Rates } \\
\hline & $\begin{array}{c}\text { No } \\
\text { education }\end{array}$ & $\begin{array}{l}\text { Primary } \\
\text { or lower } \\
\text { education }\end{array}$ & $\begin{array}{l}\text { More than } \\
\text { primary } \\
\text { education }\end{array}$ & $\begin{array}{c}\text { No } \\
\text { education }\end{array}$ & $\begin{array}{l}\text { Primary } \\
\text { or lower } \\
\text { education }\end{array}$ & $\begin{array}{c}\text { More than } \\
\text { primary } \\
\text { education }\end{array}$ \\
\hline $15-19$ & .311 & .316 & .384 & .174 & .112 & .031 \\
\hline $20-24$ & .339 & .373 & .382 & .292 & .286 & .188 \\
\hline $25-29$ & .327 & .350 & .322 & .314 & .330 & .240 \\
\hline $30-34$ & .266 & .218 & .205 & .259 & .208 & .185 \\
\hline $35-39$ & .186 & .182 & .020 & .184 & .177 & .020 \\
\hline $40-44$ & .065 & .064 & .024 & .065 & .060 & .024 \\
\hline $45-49$ & .011 & .011 & .000 & .011 & .000 & .000 \\
\hline \multicolumn{7}{|l|}{ Total } \\
\hline Fertility & 7.53 & 7.52 & 6.69 & 6.46 & 5.86 & 3.44 \\
\hline$n^{*}$ & 4208 & 374 & 272 & 4208 & 374 & 272 \\
\hline
\end{tabular}

*Unweighted number of women

Table 1 presents the age-specific fertility rates and the age-specific marital fertility rates for women with no education, those with primary or lower education, and those with more than primary schooling, for the period five years before the survey. It appears that the differentials are more marked in the TFR whereas marital fertility rates are not as different across the three groups. This is attributable to the fact that major differences in fertility across the groups are caused by variation in the nuptiality behaviour. 
Though there seems to be a slightly negative association between educational level and fertility, the effect is more apparent only for those women who achieve higher than primary schooling. These latter women have three children less than women without any schooling. Those women who have university schooling may have still lower levels of fertility but their very small sample size does not permit calculation of fertility rates for them separately.

The marital fertility rates seen in Table 1 are difficult to interpret because of differences in age at marriage across the three groups. The duration-specific fertility rates seen in Table 2 permit a comparison of fertility within marriage when duration of marriage is allowed for. Once more it is the group of women with more than primary education which has the lowest marital fertility; the other two groups have more similar levels of marital fertility. It is noteworthy that in the first five years of marriage the most educated group has a much higher level of fertility, reflecting to some extent the more rapid pace of childbearing of those who marry later [22] After twenty years of marriage, women with no education have 6.1 children whereas those with primary or less education and those with more than primary schooling have 5.9 and 5.4 children, respectively.

Table 2

Duration-specific Fertility Rates by Educational Level (For period 0-4 years preceding the Survey)

\begin{tabular}{|c|c|c|c|}
\hline $\begin{array}{c}\text { Duration : Years } \\
\text { since marriage }\end{array}$ & $\begin{array}{c}\text { No } \\
\text { Education }\end{array}$ & $\begin{array}{c}\text { Primary or } \\
\text { less }\end{array}$ & $\begin{array}{l}\text { More than } \\
\text { Primary }\end{array}$ \\
\hline $0-4$ & .293 & .331 & .390 \\
\hline $5-9$ & .348 & .349 & .295 \\
\hline $10-14$ & .314 & .317 & .207 \\
\hline $15-19$ & .259 & .178 & .184 \\
\hline $20-24$ & .178 & .165 & .037 \\
\hline $25-29$ & .070 & .081 & .032 \\
\hline $30-34$ & .010 & .000 & .000 \\
\hline Total & 7.36 & 7.11 & 5.73 \\
\hline & 4203 & 385 & 270 \\
\hline
\end{tabular}

No. of Children after

20 years of marriage

6.1

5.9

5.4

Thus far the discussion has concerned differentials in recent fertility. We look now in Table 3 at cumulative fertility, which is measured by the number of children ever born to women belonging to a certain cohort up to the time of the survey, and the differentials by the level of mother's education. A clear inverse relationship is found between mean parities for all women by educational level, with only a handful of exceptions.

Table 3

Mean Parities for Ever-married and All Women* by Age and Education

\begin{tabular}{|c|c|c|c|c|c|c|c|c|}
\hline & \multicolumn{8}{|c|}{ Age Groups } \\
\hline & $15-19$ & $20-24$ & $25-29$ & $30-34$ & $35-39$ & $40-44$ & $45-49$ & Total \\
\hline \multicolumn{9}{|c|}{ No Schooling } \\
\hline \multicolumn{9}{|l|}{ Ever-married } \\
\hline \multirow[t]{2}{*}{ Women } & 1.59 & 1.97 & 3.45 & 5.00 & 6.15 & 7.02 & 6.93 & 4.28 \\
\hline & $(554)$ & $(722)$ & (794) & (731) & $(566)$ & $(582)$ & $(175)$ & (4424) \\
\hline \multirow[t]{2}{*}{ All women } & .266 & 1.65 & 3.22 & 4.84 & 6.03 & 6.95 & 6.96 & \\
\hline & \multicolumn{8}{|c|}{ Primary or Less Education } \\
\hline \multicolumn{9}{|l|}{ Ever-married } \\
\hline \multirow[t]{2}{*}{ Women } & .54 & 1.48 & 3.23 & 5.19 & 5.24 & 6.79 & 5.43 & 3.36 \\
\hline & $(57)$ & (71) & $(68)$ & $(58)$ & $(33)$ & (29) & (17) & (333) \\
\hline \multirow[t]{2}{*}{ All women } & .14 & 1.02 & 2.88 & 5.05 & 5.11 & 5.56 & 5.20 & \\
\hline & \multicolumn{8}{|c|}{ More than Primary Education } \\
\hline \multicolumn{9}{|l|}{ Ever-married } \\
\hline \multirow[t]{2}{*}{ Women } & .32 & 1.58 & 2.32 & 3.93 & 4.49 & 4.85 & 6.18 & 2.83 \\
\hline & $(17)$ & $(50)$ & $(52)$ & $(31)$ & $(25)$ & (9) & (12) & $(196)$ \\
\hline All women & .02 & .60 & 1.68 & 3.21 & 3.97 & 4.85 & 6.18 & \\
\hline
\end{tabular}

*Inflated by proportions married.

Figures in brackets represent the number of cases.

For ever-married women, mean parities show a mixed picture: for the age group 20-24, mean parity of the most educated group is somewhat higher than for the intermediary group and once again for the age group 30-34, mean parity is higher for the intermediary group than that for the uneducated group. The overall means, however, point to an inverse relationship. Apart from considering age as a control it is essential to assess whether age-at-marriage differentials may be causing differences in fertility across educational groups. Another important confounding factor may well be residence. As pointed out in the introduction, about three-fourths of the population in Pakistan, despite recent rapid urbanization, lives in rural areas and the chance of acquiring education is much lower in rural areas. Table 
4 presents the mean of children ever born, unadjusted and then adjusted in turn for age, age at marriage and residence. (Adjustment was made using Multiple Classification Analysis where the number of children ever born was the dependent variable and age, age at marriage and residence were introduced as independent factors in turn.) Allowing for age and age at marriage reduces the educational differentials for the mean number of children ever born whereas the addition of residence to these controlling variables actually enhances the differentials. This is thought to be due to the stronger negative effect of education on rural fertility and the higher marital fertility in urban areas.

Table 4

Mean Number of Children ever born by Mother's Educational Level, adjusted for Age, Age at Marriage, and Residence

\begin{tabular}{lcccc}
\hline Mother's & \multicolumn{4}{c}{ Mean number of children ever born } \\
\cline { 2 - 5 } Education & Unadjusted & $\begin{array}{c}\text { Adjusted } \\
\text { for age }\end{array}$ & $\begin{array}{c}\text { Adjusted for } \\
\text { age at marriage }\end{array}$ & $\begin{array}{c}\text { Adjusted for } \\
\text { residence }\end{array}$ \\
\hline No education & 4.28 & 4.22 & 4.18 & 4.19 \\
Primary or less & 3.36 & 3.92 & 4.12 & 4.05 \\
More than primary & 2.83 & 3.30 & 3.88 & 3.72 \\
\hline
\end{tabular}

Thus far fertility rates have been compared on the basis of live births per woman or by children ever born. In many respects it is important also to look at measures of how many children women can expect to lose through infant and child mortality as it can be argued that the number of surviving children is crucial in terms of a family's fertility desires. Infant mortality is very high (140 deaths per 1000 live births) despite falls in mortality. It has often been argued that such high levels of infant mortality are conducive to high fertility as parents, by having a large family, seek to ensure that at least a certain number of their children will survive till adulthood [19]. The argument presumes volitional behaviour which, though intuitively acceptable, is hard to establish in a largely natural fertility regime like Pakistan's. Such considerations are likely to motivate educated parents to have fewer births to ensure that their children have a greater likelihood to survive. Table 5 shows that educated mothers do in fact experience much lower levels of infant and child mortality. Interestingly enough, the sex differential in infant mortality is reversed in the case of educated women, with female children of educated mothers having a better chance of surviving till the ages of 1 and 5 .
Table 5

Infant and Child Mortality by Mother's Education

\begin{tabular}{lcc}
\hline Mortality & No education & Some education \\
\hline Infant mortality $\left.\left(q_{1}\right)_{0}\right)^{1}$ & .146 & .120 \\
All children & .135 & .126 \\
Males & .157 & .115 \\
Females & & \\
& & .148 \\
Child mortality $\left({ }_{5} q_{0}\right)^{2}$ & .205 & .148 \\
All children & .206 & .147 \\
Males & .205 & \\
Females & & \\
\hline
\end{tabular}

${ }^{1}$ Rate based on the period of $0-4$ years before the survey.

${ }^{2}$ Rate based on the period of 5-9 years before the survey.

Most parents in traditional societies favour having large families and concurrently with high infant mortality an even larger number needs to be borne to ensure that the desired number survives. If the impact of infant mortality is experienced more acutely by uneducated mothers, it should be one of several reasons why they desire a larger number of children than are desired by educated women. Table 6 shows figures representing fertility desires amongst educated and uneducated women. It is clear that as far as answers to questions about preferences for family size are representative of actual desires, educated women seemed to want smaller families. This holds true even when age or the number of living children is controlled. Thus there is evidence that educated women in Pakistan reported consistently lower fertility preferences.

\section{The Intermediate Fertility Variables}

Any actual effects of education on fertility are transmitted through a set of variables referred to as intermediate variables. Although the influence of these variables on fertility is direct, it is not necessarily in the same direction: some may influence fertility in a positive way, while others inhibit it. A large amount of fertility variation is found to exist across societies and within sub-groups constituting them. Some of the variation can be explained by the degree of fertility control used but some differences are attributable to differing levels of natural fertility in the societies in question [11]. This variation in 'natural fertility' lies in differences in the intermediate variables which collectively determine the levels of fertility in a society. 
Table 6

Mean Number of Children desired, by Mother's Age, Number of Living Children and Educational Level

\section{A. By Mother's Age}

\begin{tabular}{lcccccccc}
\hline & \multicolumn{7}{c}{$\begin{array}{c}\text { Mean Number of Children desired when Mother's } \\
\text { Age (in years) is }\end{array}$} \\
$\begin{array}{l}\text { Mother's } \\
\text { Education }\end{array}$ & $15-19$ & $20-24$ & $25-29$ & $30-34$ & $35-39$ & $40-44$ & $45-49$ & Total \\
\cline { 2 - 8 } & & & & & & & 4.5 & 4.3 \\
$\begin{array}{l}\text { No } \\
\text { education }\end{array}$ & 4.2 & 4.2 & 4.3 & 4.3 & 4.5 & 4.5 & 4.4 & \\
$\begin{array}{l}\text { Primary or } \\
\text { less }\end{array}$ & 3.5 & 3.4 & 3.7 & 4.0 & 3.9 & 3.7 & 4.0 & 3.7 \\
$\begin{array}{l}\text { More than } \\
\text { primary }\end{array}$ & 3.3 & 3.1 & 3.4 & 3.4 & 3.2 & 3.8 & 3.6 & 3.3 \\
\hline
\end{tabular}

\section{B. By Number of Living Children}

Mean Number of Children desired when the Number of Living Children is

Mother's

\begin{tabular}{lcccccccc} 
Education & 0 & 1 & 2 & 3 & 4 & 5 & 6 & $7+$ \\
\hline $\begin{array}{l}\text { No } \\
\text { education }\end{array}$ & 4.0 & 3.9 & 4.0 & 4.1 & 4.4 & 4.5 & 4.5 & 4.8 \\
$\begin{array}{l}\text { Primary or } \\
\text { less }\end{array}$ & 3.4 & 3.3 & 3.5 & 3.8 & 3.9 & 3.8 & 3.9 & 4.2 \\
$\begin{array}{l}\text { More than } \\
\text { primary }\end{array}$ & 3.3 & 3.2 & 2.9 & 3.0 & 3.4 & 3.5 & 3.4 & 3.4 \\
\hline
\end{tabular}

The framework of intermediate variables outlined by Davis and Blake [8] is followed broadly to discuss some of the factors which may explain the impact of education on behaviour which leads to these differences in fertility. Age at marriage and effective entry into a sexual union have already been mentioned as factors responsible for a large proportion of the differences in fertility by education. Permanent celibacy is almost non-existent amongst Pakistani women and regardless f educational attainment most women marry by the age of 35 . This characteristic of educational attainmes in economic circumstances; as females become more independent financially and suitable marriage partners become more become more inderion not to marry. Table 7 presents the proportions of females ever married by educational level along with the singulate mean age at marriage for these groups.

Table 7

Proportions of Females ever married by Educational Level (1975)

\begin{tabular}{lccc}
\hline Age Groups & No education & $\begin{array}{c}\text { Primary or less } \\
\text { education }\end{array}$ & $\begin{array}{c}\text { More than primary } \\
\text { education }\end{array}$ \\
\hline $10-14$ & .017 & .000 & .000 \\
$15-19$ & .448 & .261 & .060 \\
$20-24$ & .840 & .694 & .381 \\
$25-29$ & .933 & .891 & .724 \\
$30-34$ & .969 & .974 & .815 \\
$35-39$ & .981 & .975 & .884 \\
$40-44$ & .990 & .966 & 1.000 \\
$45-49$ & .995 & .958 & 1.000 \\
Singulate Mean & & & 25.7 \\
Age at Marriage & 19.2 & 21.4 & \\
\hline
\end{tabular}

The differences in singulate mean age at marriage and proportions marrying at earlier ages are indeed striking. The positive relationship between educational level and age at marriage is not entirely due to postponement of marriage owing to school attendance because even the event of having completed primary education leads to a rise in the mean age at marriage. Much of the effect of schooling on later age at marriage is thought to be indirect [12]. Such similar considerations as changes in attitudes and values and economic reasons which lead to higher age at marriage amongst educated women may be operating through residence: urban women were found to be marrying a year and a half later than rural women [2]. Entry into union is later for educated women but in actual fact the reported date of marriage may be the official ceremony (nikah) which may transpire earlier than cohabitation (rukhsati). It is more likely that when age at marriage is higher, as in the case of educated women, the gap between the two occasions will be smaller than in the case of women who marry very early, especially before puberty.

Within a union, exposure is determined by levels of involuntary or voluntary infertility. Several post-partum practices are thought to lead to quite long spacing 
between births of children. For instance, both the practice of post-partum abstinence of at least 40 days prescribed in Islam and the frequent absence of the wife to deliver children in her maternal home can lead to large gaps before normal level of intercourse is resumed after a birth. Although no direct evidence is available for such behaviour in Pakistan, there is evidence from other traditional societies which indicates that rural and uneducated women are more likely to adhere to longer post-partum periods of abstinence than educated, urban women [5]. Similar patterns could apply in Pakistan and consequently lead to longer spacing between births in rural areas and amongst uneducated women. The evidence supporting this is positive [22]. Longer spacing would, of course, act to inhibit fertility levels of uneducated women.

Spousal migration is another source of involuntary abstinence; male migration from rural to urban areas is a very common phenomenon in Pakistan. Often men and their families are separated for a full year or more. External migration, especially to the Middle East, has become very common recently. Once again mostly males alone (regardless of marital status) migrate. Over prolonged periods, this is bound to have some reducing effect on fertility but we need data on length of stay before we may be able to make any accurate assessment of this effect. However, it is worth mentioning that spousal separation is likely to affect uneducated and rural women more than educated urban women, as most educated persons who migrate usually do so with their families to the Western countries. Thus, the lowering of their fertility would be inconsequential to the fertility levels of Pakistan as a whole.

Coital frequency is a factor which strongly affects fecundability but is very hard to measure. Direct questions on this subject have never been asked in Pakistan; however, we may speculate that those living in extended households do have very little privacy and this may inhibit coital frequency. But overcrowding in nuclear households and the likely presence of older children in the same room may also be an inhibiting factor. There is, of course, no reason to believe that except under different constraints of sleeping space, educated couples will have lower or higher coital frequency than uneducated ones. An attempt to estimate fecundability indirectly seemed to indicate that the group with more than primary schooling has much higher fecundability [22]. But this finding may well have been influenced by the effects of possible earlier cohabitation after marriage amongst educated women.

There are a number of factors associated with sterility, which is of three kinds: adolescent, primary and secondary. The first affects girls who marry at very early ages and is temporary; educated women are less likely to be affected by it as they marry much later. Primary sterility usually affects a small proportion in each population who can never bear any children. Secondary sterility is the decline of fecundity in the later period of childbearing as women approach menopause. The only evidence of adolescent sterility is the lower proportion of women who conceive within one year of marriage among those who marry before the age of 15. The prevalence of primary sterility is estimated by proportions childless after age 35: it was found that 3.9 percent of those with no education, 4.3 percent of those with primary or less schooling, and 6.4 percent with more than primary schooling had no births. This seemed to suggest a positive association between sterility and level of education, but owing to the small numbers on which the last percentage is based, this finding is subject to sampling errors. Among women above age 35 , the corresponding women who answered negatively to the question whether or not she and her husband could have another birth if they wanted amounted to 12 percent, 6 percent and 5 percent. These data point to the more expected negative association between level of education and sterility, at least as it was perceived by the women themselves.

Most women become totally sterile by the age of 50 but the average age at menopause has been found to vary across societies [11]. It is especially difficult to estimate the average age at menopause because older couples are thought to practise abstinence in the presence of married children, especially grandchildren, in the same household. Moreover, voluntary and involuntary causes of the onset of secondary sterility are hard to discern. About 32 percent of women above 35 , with negligible differences across educational groups, who were not practising any form of contraception, reported no births in the last 5 years.

Another important source of infecundity is caused by post-partum amenorrhoea which directly determines the length of birth intervals. Breast-feeding is found to be strongly positively correlated with the amenorrhoeic period after the birth of a child. It was found that most women in Pakistan breast-feed all of their children but the average length of lactation varies by age and socio-economic characteristics of the mother. Reported lengths of lactation are hard to interpret because women who report long periods of breast-feeding may have in fact begun to rely partially at least on other feeds such as powdered milk. Artificial feeding has been encouraged in arban areas by widespread advertisement, and it may be more likely that urban and educated women may be combining and/or substituting breastfeeding with other feeds which may be more popular owing to the advice of doctors, clinics, etc. Since the amenorrhoeic effect of lactation probably operates through the intensity of suckling, introduction of supplementary feeding may reduce this effect. Variations in lactational behaviour then become a major explanatory variable of differences in potential fertility across educational groups.

Some problems of measuring the length of lactation are discussed elsewhere $[14 ; 24]$; the main aspect of lactation in which we are interested is its relationship with infecundability. Here we have used Bongaarts's formula to estimate lactational infecundability. 


$$
i=e^{0.56126}+0.1396 \mathrm{x}-0.001872 \mathrm{x}^{2}
$$

where $x$ is the median length of lactation [4]. It was found that the average period of infecundability was 17.6 months for women without schooling and 13.0 months for those with primary or less schooling. The equivalent figure could not be computed directly for women who had more than primary schooling because of their small numbers, but it is expected to be shorter than 13 months. Thus, it seems evident that length of breast-feeding, which strongly reflects differences in social and personal behaviour, is associated with educational level. However, unlike marriage behaviour, the association of educational level and breast-feeding leads to fertilityincreasing effects through reduced periods of lactational infecundability.

As mentioned earlier, levels of fertility are also determined by the degree of deliberate attempts to control fertility as well as levels of natural fertility. The level of reported contraceptive use in Pakistan is generally found to be very low: only 10 percent of currently married women report ever using any method while about 7 percent report current use [25]. A strong, direct relationship was identified between contraceptive use and women's educational level. While 5.9 percent of women who have no education report current use, the corresponding figures for those women with primary or less education and for those with more than primary education are 12.9 percent and 29.1 percent, respectively. Also, educated women are found to be more knowledgeable about contraceptive methods than uneducated women owing to their greater exposure to mass media and the spread effect of information through friends, relatives, etc.

Another source of variation of fertility would be the differences in adoption of abortion as a way of dealing with unwanted pregnancies. It is interesting to report that although questions were asked about both spontaneous and induced abortions, not a single woman in the PFS reported an induced abortion. Strong taboos in a religious society like Pakistan may be preventing a woman from admitting having an abortion to a stranger but undoubtedly some must take place if for no other reason than the medical ones. Abortions are legally permissible on medical grounds, although there is a strong social pressure against it. It may be possible that induced abortions are being reported as spontaneous, especially in rural areas where self-inducement methods are more widespread as compared to clinic abortions which would have been more clearly discernible as induced abortions. But this is hard to confirm. If the incidence of abortion is expected to be correlated with socio-economic status and, consequently, with education, the lack of data on this topic then undoubtedly presents a gap in the explanation of differential fertility.

The average number of wasted pregnancies per woman was higher amongst educated women than among uneducated women. This is surprising as we would expect better health conditions amongst educated women who should consequently experience a lower foetal loss rate. Also, it would be expected that educated women have a smaller number of pregnancies on average than uneducated women and the only possible explanation of higher levels of pregnancy wastage amongst educated mothers would be more marked omissions in reporting of foetal loss by uneducated women.

Finally, we utilize the Bongaarts framework developed to analyse the effect of the major intermediate variables on fertility and to assess their impact on differentials in fertility by education [3]. The four variables selected by Bongaarts, on the basis of the sensitivity of fertility to variation within them, are proportions married amongst females, contraceptive use, prevalence of induced abortions and duration of post-partum infecundability. They are each measured by an index which takes on a value between zero and one; when the particular intermediate variable has no inhibiting effect its index acquires a value of one and if inhibition is complete it acquires a value of zero.

Table 8 presents Bongaarts's indices, wherever calculable for different levels of educational attainment. The index for abortion could not be computed owing to no reported incidence of abortion as discussed earlier.

Table 8

Bongaarts's Indices by Mother's Educational Level

\begin{tabular}{lccc}
\hline \multirow{3}{*}{ Indices } & \multicolumn{3}{c}{ Mother's Education } \\
\cline { 2 - 4 } & No schooling & Primary or less & More than primary \\
\hline $\mathrm{Cc}$ & .946 & .882 & .734 \\
$\mathrm{Ci}$ & .603 & .635 & $.670^{1}$ \\
$\mathrm{Cc} \times \mathrm{Ci}$ & .570 & .560 & .491 \\
$\mathrm{Cm}$ & .872 & .847 & .695 \\
$\mathrm{Cc} \times \mathrm{Ci} \times \mathrm{Cm}$ & .497 & .474 & .324 \\
\hline
\end{tabular}

${ }^{1} \mathrm{~A}$ value of .670 for $\mathrm{Ci}$ for the "more than primary schooling" group was utilized.

Note: $\mathrm{Cm}=$ Index of proportions married; $\mathrm{Cc}=$ index of contraceptive use; $\mathrm{Cl}=$ Index of post-partum infecundability; and $\mathrm{Ca}=$ Index of induced abortion.

Since the model is multiplicative, the overall effect of respondent's education on $\mathrm{Ci}$ and $\mathrm{Cc}$ is to cause little difference in marital fertility between women with no education and those with less than primary education. Undoubtedly differences may have been larger in the case of women with more than primary education, but $C t$ could not be computed for that group and we arbitrarily use a figure of .670 (as $C$ for women of this group is bound to exceed that for women of the "primary or less schooling" group by at least as much as the $\mathrm{Ci}$ for the latter women exceeds that for uneducated women) and it points to the much stronger impact of $\mathrm{Ci}$ and $\mathrm{Cc}$ on this most educated group. Once $\mathrm{Cm}$ is introduced into the model, estimated differentials 
are slightly greater between the uneducated and "primary or less schooling" groups but are greater still for the "more than primary schooling" group.

\section{CONCLUSIONS AND POLICY IMPLICATIONS}

It therefore appears that there are some significant associations between educational level of women and their attitudes and behaviour related to fertility. Educated women marry later, desire fewer children 'bear fewer births', lose less children through death at earlier ages, breast-feed for shorter durations, and use contraception more than uneducated women. The sometimes conflicting effects of the intermediate variables, associated with particular levels of education on fertility, explain to some extent why every additional level of education may not be associated with a reduction in fertility. For instance, education in Pakistan is associated with shorter lengths of post-partum amenorrhoea and consequently earlier resumption of menses, which lead to shorter birth intervals and higher marital fertility. Less frequent spousal separation and higher fecundability (though just speculated as being associated with educated women) would also have fertilityincreasing effects. On the other hand, later ages at marriage, lower proportions married and higher contraceptive use are associated positively with increased education and have a fertility-reducing effect.

An interesting finding was that women in urban areas had higher marital fertility than women in rural areas with equivalent levels of education. It was found that in contrast to most other countries the impact of education was greater in rural areas than in urban areas [7]. Marital fertility has already been established to be higher in urban areas $[6 ; 21]$ and is thought to be due to the breakdown in traditionally long periods of breast-feeding and abstinence that prevail in rural areas. But another factor at work may be the differences in the educational structure in urban and rural areas. Thus the smaller chances of acquiring any education for rural females compared to those for the urban ones may imply that a different relative socio-economic status would be related with the same educational level in the two areas. This idea is highly credible, as even a minimal level of education amongst rural females would reflect a higher socio-economic status and stronger motivation of parents to send their daughters to school than prevail in urban areas where there are more schools and the overall motivation to educate children of both sexes is generally greater,

Therefore, in conclusion we are inclined to think that female education does in fact bear an association with fertility, owing to the fact that it is strongly interwoven with other social and economic measures such as class, income, modernization, residence, etc. However, the effects of education thus far in Pakistan are seen more clearly in differences in measures of the intermediate variables, rather than in actual fertility differentials. This lack of differentials is thought to be largely due to very few women in the sample with more than primary education, the level which seems to be critical for changes in fertility behaviour. The proportion of females that reaches this level of education continues to be very small owing to the lack of a rapid enough increase in enrolment rates. Thus the Government ought to bear in mind that only very concerted efforts at raising overall educational levels of females, at least beyond primary schooling, will bring about changes in national levels of fertility. At least until now the achievements in educating women in Pakistan have not contributed significantly to lowering fertility in the country.

\section{REFERENCES}

1. Afzal, M., Zubeda Khan and Naseer Chaudhry. "Age at Marriage, Fertility and Infant Child Mortality in a Lahore Suburb-Part I". Pakistan Development Review. Spring 1976.

2. Alam, Iqbal. "Fertility Levels and Trends". In Iqbal Alam and Betzy Dineson (eds.), Fertility in Pakistan: A Review of Findings from the Pakistan Fertility Survey. Voorburg, Netherlands: International Statistical Institute. 1984.

3. Bongaarts, J. "A Framework for Analyzing the Proximate Determinants of Fertility". Population and Development Review. Volume 4, No. 1. 1978.

4. Bongaarts, J., and S. Kirmeyer. "Estimating the Impact of Contraception Prevalence on Fertility: Aggregate and Age Specific Versions of a Model". New York: The Population Council. 1981. (Working Paper No. 62)

5. Caldwell, J. "The Role of Marital Sexual Abstinence in Determining Fertility: A Study of the Yoruba in Nigeria". Population Studies. Vol. 31, No. 2. 1977.

6. Casterline, J. "Fertility Differentials". In Iqbal Alam and Betzy Dineson (eds.), Fertility in Pakistan: A Review of Findings from the Pakistan Fertility Survey Voorburg, Netherlands: International Statistical Institute. 1984.

7. Cochrane, S. Fertility and Education: What Do We Really Know? Baltimore: Johns Hopkins University Press. 1978.

8. Davis, K., and J. Blake. "Social Structure and Fertility". Economic Development and Cultural Change. Vol. 4, No. 3. 1956.

9. Duza, B. "Differential Fertility in Pakistan". In W. Robinson (ed.), Studies in the Demography of Pakistan. Karachi: Pakistan Institute of Development Economics. 1967.

10. Graff, H. "Literacy, Education, and Fertility, Past and Present: A Critical Review". Population and Development Review. Vol. 5, No. 1. 1979.

11. Henry, L. "Some Data on Natural Fertility". Eugenics Quarterly. Vol. 8, No. 2. 1961.

12. Karim, M. "Female Nuptiality and Fertility in Pakistan". Unpublished Ph.D. Thesis, Cornell University. 1980. 
13. Khan, M. Ali, and I. Sirageldin. "Education, Income and Fertility in Pakistan" Economic Development and Cultural Change. Vol. 27, No. 3. 1979.

14. Lesthaege, R., and H. Page. "The Post-partum Non-susceptible Period: Development and Application of Model Schedules". Population Studies. Vol. 34, No. 1. 1980.

15. Mahmood, N. "Literacy and Educational Attainment Levels". Pakistan Development Review. Vol. XVII, No. 3. Autumn 1978.

16. Pakistan. Planning Commission. Working Papers for the Fifth Five Year Plan (1977-83) Parts I and II. Islamabad. October 1976.

17. Pakistan Population Planning Council. World Fertility Survey: Pakistan Fertility Survey. Islamabad. 1976.

18. Pasha, H., K. Hyer and R. Arshad. "Education and Employment in Pakistan". In Employment Planning and Basic Needs in Pakistan, Report of a National Conference held at Islamabad, May 1978.

19. Preston, S. (ed.), The Effects of Infant and Child Mortality on Fertility. New York: Academic Press. 1978.

20. Research Triangle Institute. "Turkish Fertility: A Review of Social and Economic Correlates”. Research Triangle Park, N. Carolina. 1972.

21. Sathar, Z. "Rural-Urban Fertility Differentials: 1975". Pakistan Development Review. Vol. XVIII, No. 3. Autumn 1979.

22. Sathar, Z. "Birth Spacing in Pakistan". Paper presented in the WFS Workshop in East-West Center, Honolulu (Hawaii). 1981.

23. Sathar, Z. "Education and Fertility in Pakistan". Unpublished Ph.D. thesis, University of London. 1982.

24. Shah, I. "Socio-Economic Differentials in Breastfeeding". In Iqbal Alam and Betzy Dineson (eds.), Fertility in Pakistan: A Review of Findings from the Pakistan Fertility Survey. Voorburg, Netherlands: International Statistical Institute. 1984.

25. Shah, N., and M. Shah. "From Non-use to Use: Prospects of Contraceptive Adoption in Pakistan". In Iqbal Alam and Betzy Dineson (eds.), Fertility in Pakistan: A Review of Findings from the Pakistan Fertility Survey. Voorburg, Netherlands: International Statistical Institute. 1984.

26. Timur, S. "Demographic Correlates of Women's Education". IUSSP Conference, IPC proceedings Vol. III. Mexico. 1977.

27. World Bank. "Pakistan: Population Planning and Social Services". Washington, D.C. 1978. (Report No. 2018)

28. Zaidi, A. "Fertility in Relation to the Educational Status of Husbands and Wives in Lahore". Lahore: University of Punjab. 1962. 